\title{
Synthesis of Star-shaped 8 arms Poly(ethylene glycol)-Poly(L-lactide) Block Copolymer and Physicochemical Properties of Its Solution Cast Film as Soft Biomaterial
}

\author{
Koji Nagahama, Yuichi OHYA, ${ }^{\dagger}$ and Tatsuro OuCHI ${ }^{\dagger}$ \\ Department of Applied Chemistry, Faculty of Engineering and High Technology Research Center, \\ Kansai University, Suita, Osaka 564-8680, Japan
}

(Received February 24, 2006; Accepted May 2, 2006; Published July 14, 2006)

\begin{abstract}
Biodegradable star-shaped 8 arms PEG- $b$-PLLA block copolymer was synthesized to create a novel implantable soft material. The differences in physicochemical properties between star-shaped 8 arms PEG10K- $b$ PLLA35K film and linear 2 arms PEG10K- $b$-PLLA33K film having same compositions of PEG and PLLA units was investigated to reveal the architecture effects on their physicochemical properties. Thermal analysis of these copolymer films revealed that the crystallinity of PLLA in the 8 arms PEG10K- $b$-PLLA35K films (1.8\%) was drastically low compared with that in the 2 arms PEG10K- $b$-PLLA33K film (37.5\%). Additionally, TEM observation of the copolymer films revealed that the larger PLLA domains (greater than $200 \mathrm{~nm}$ ) with miscellaneous structure were formed in the 2 arms PEG10K- $b$-PLLA33K film while the smaller PLLA domains $(80 \mathrm{~nm})$ with lamellar structure were formed in the 8 arms PEG10K- $b$-PLLA35K film. Consequently, the 8 arms PEG10K- $b$-PLLA35K film showed higher swelling ability, lower tensile strength and higher elongation at break than the 2 arms PEG10K- $b$-PLLA33K film. Moreover, the 8 arms PEG35K- $b$-PLLA37K film showed higher elongation at break than the 8 arms PEG10K- $b$-PLLA35K film because of the fine PLLA domains with highly ordered structure. The 8 arms PEG35K- $b$-PLLA37K film which having the high swelling ability and desirable mechanical properties such as softness as well as tenacity was available as a novel implantable soft material. [doi:10.1295/polymj.PJ2005240]

KEY WORDS 8 arms Poly(ethylene glycol) / Poly(L-lactide) / Star-shaped Block Copolymer / Biodegradable / Soft Biomaterial /
\end{abstract}

Biodegradable, biocompatible synthetic polymers have become of interest from standpoints of biomedical and pharmaceutical applications. Poly(L-lactide) (PLLA) is one of the most accessible biomedical polymers in terms of its biodegradability, biocompatibility and good shaping-molding property. In fact, PLLA is known as an implant with a long life span, and until now no marked shortcoming or problems related to toxicity, severe acute inflammation and immunogenicity have been reported. However, the use of PLLA has been limited to hard tissue treatment as bone plates, rods and screws, and its application to soft tissue treatment has been hindered because of the stiffness which accompanies the high crystallinity. ${ }^{1}$ Therefore, various modifications have been made to control the crystallinity. ${ }^{2-7}$ One approach is to hybridize hydrophilic polymer such as polysaccharide or poly(ethylene glycol) (PEG) as soft segment to PLLA. In practice, we reported previously the synthesis of graft copolymers composed of PLLA and polysaccharides such as pullulan or dextran through ring-opening anionic polymerization of L-lactide using the corresponding trimethylsilyl polysaccharide as an macroinitiator. ${ }^{8-10}$
As the results, the degradation rate of the obtained polymers could be controlled with changing the crystallinity of PLLA by varying hydrophilic sugar content in polysaccharide-grafted PLLA.

Recently, various block copolymers consisting of PLLA and PEG have been reported to be applied as biodegradable biomaterials. ${ }^{11-16}$ Generally speaking, it is known that non-biodegradable PEG must be eliminated by the kidneys in order to prevent accumulation inside the body. This fact clearly limits the use of linear PEG, which has a molecular weight of more than 20,000, even though the use of high molecular weight PEG is required to control the composition of PEG-PLLA block copolymer, which in turn governs the water absorption ability and mechanical properties of the product. Star-shaped polymers are known to exhibit a smaller hydrodynamic radius compared with linear polymers of the same molecular weight. Given this hydrophilic 8 arms PEG having a star-shaped structure is presumed to have a smaller hydrodynamic radius than the corresponding linear 2 arms PEG. A smaller hydrodynamic radius of the 8 arms PEG in aqueous media is important in terms

${ }^{\dagger}$ To whom correspondence should be addressed (Tel: +81-6-6368-0814, Fax: +81-6-6339-4026, E-mail: touchi@ipcku.kansai-u.ac.jp, yohya@ipcku.kansai-u.ac.jp). 


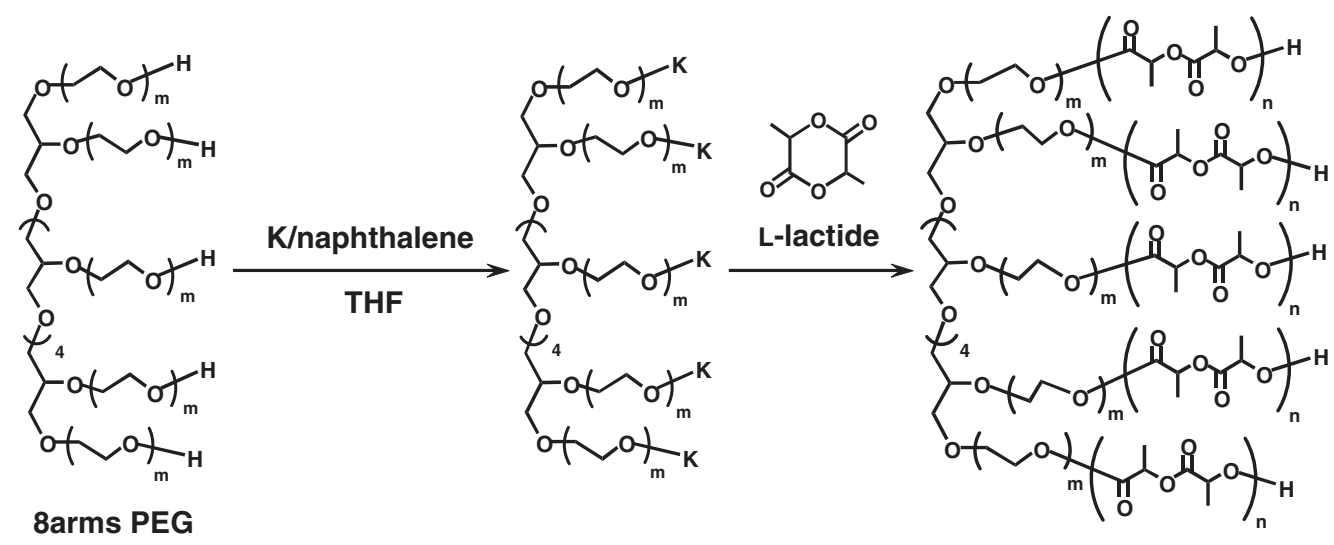

8arms PEG- $b$-PLLA

Scheme 1. Synthetic route of star-shaped 8 arms PEG-PLLA block copolymer.

of its complete renal excretion, which is vital as an implantable biomedical material having bioabsorbability. This may allow for the use of 8 arms PEG35K with a small hydrodynamic radius enough for renal excretion in the design of biocompatible PEG-PLLA block copolymers. So, the matrix prepared from the 8 arms PEG35K-PLLA block copolymer was expected to show high water absorption ability as well as elastic nature because the formation of PLLA network was presumed by introducing star-shaped structure.

The objective of this study is to synthesis of amphiphilic star-shaped 8 arms PEG-PLLA block copolymer ( 8 arms PEG- $b$-PLLA) and to reveal the molecular architecture effects of star-shaped 8 arms PEG10K$b$-PLLA35K and linear 2 arms PEG10K- $b$-PLLA33K films on their thermal property, water absorption ability, degradation rate and mechanical property. In addition, water absorption ability, mechanical property and microphase separated structure of the 8 arms PEG35K- $b$-PLLA37K film were compared with those of the 8 arms PEG10K- $b$-PLLA37K to explore the potential of a star-shaped 8 arms PEG35K- $b$-PLLA37K film as a novel implantable soft material which stretched well after absorbed a lot of water.

\section{EXPERIMENTAL}

\section{Materials}

L-Lactide was purchased from PURAC. 8 arms PEG $\left(M_{\mathrm{n}}=1.0 \times 10^{4}, 2.0 \times 10^{4}, 3.5 \times 10^{4}, M_{\mathrm{w}} /\right.$ $\left.M_{\mathrm{n}}=1.2\right)$ and $2 \operatorname{arms}$ PEG $\left(M_{\mathrm{n}}=1.0 \times 10^{4}, 2.0 \times\right.$ $\left.10^{4}, M_{\mathrm{w}} / M_{\mathrm{n}}=1.1\right)$ were supplied by NOF Co. LLactide, 8 arms PEG and 2 arms PEG were sufficiently dried under vacuum before use. Dry THF purchased from Wako Pure Chemical was used as a polymerization solvent. Other organic solvents were used without further purification.

\section{Dynamic Light Scattering Measurement}

Dynamic light scattering (DLS) measurements were carried out at $37^{\circ} \mathrm{C}$ on a DLS-7000 apparatus (Otsuka Electronics Co.) with vertically polarized incident light with a wavelength of $488 \mathrm{~nm}$ supplied by an argon laser operated at $15 \mathrm{~mW}$. $50 \mathrm{mg}$ of 8 arms PEG $\left(M_{\mathrm{n}}=1.0 \times 10^{4}, 2.0 \times 10^{4}\right.$ and $\left.3.5 \times 10^{4}\right)$ or $2 \mathrm{arms}$ PEG $\left(M_{\mathrm{n}}=1.0 \times 10^{4}\right.$ and $\left.2.0 \times 10^{4}\right)$ was dissolved in $4.5 \mathrm{~mL}$ of water (Milli-Q grade), and then the PEG aqueous solution was filtered through Durapore (Millipore) $0.45 \mu \mathrm{m}$ membrane prior to measurement.

\section{Synthesis of Star-shaped Block Copolymers}

Star-shaped 8 arms PEG-PLLA block copolymer ( 8 arms PEG- $b$-PLLA) was synthesized by ring-opening anionic polymerization of L-lactide using 8 arms PEG as an octafunctional macroinitiator, as shown in Scheme 1. The following anionic polymerization was carried out in a glove box purged with dry argon. The eight hydroxyl end groups of 8 arms PEG were transformed to the potassium alkoxide end groups with potassium (K)/naphthalene in dry THF. Naphthalene $(256 \mathrm{mg} ; 300 \mu \mathrm{mol})$ and small amount potassium were added to dry THF $(2.0 \mathrm{~mL})$ and then stirred to obtain a THF solution of $\mathrm{K} /$ naphthalene (deep green). $1 \mathrm{~mL}$ of $\mathrm{K} /$ naphthalene of THF solution was added to the THF solution $(11.0 \mathrm{~mL})$ of $8 \mathrm{arms}$ PEG10K ( $250 \mathrm{mg}$; $200 \mu \mathrm{mol}$ of end hydroxyl groups) and stirred for $60 \mathrm{~min}$ to prepare the potassium alkolate of 8 arms PEG10K, 8 arms PEG10K-OK. $12 \mathrm{~mL}$ of L-lactide $(24.0 \mathrm{mmol})$ of THF solution was added to the resulting 8 arms PEG10K-OK solution. After $15 \mathrm{~min}$, the block copolymerization of L-lactide was terminated by addition of $24 \mu \mathrm{L}$ of acetic acid $(400 \mu \mathrm{mol})$ to the reaction mixture. The obtained product was reprecipitated three times with chloroform/diethyl ether and dried under vacuum overnight to obtain the white solid 8 arms PEG10K- $b$ - 
PLLA35K. As the control copolymer, ABA type linear PLLA17K-PEG10K-PLLA17K block copolymer (2 arms PEG10K- $b$-PLLA33K) was synthesized using the same procedure described above. Molecular weight distribution $\left(M_{\mathrm{w}} / M_{\mathrm{n}}\right)$ of synthesized block copolymers was estimated by gel permeation chromatography [GPC; Tosoh GPC-8020 series system (column: TSK-GEL ALPHA-5000 $\times 2$, eluent: DMF, detector: refractive index, standard: PEG)]. $M_{\mathrm{n}}$, the degree of polymerization (DP) of L-lactide and the PEG content in the block copolymer were estimated by ${ }^{1} \mathrm{H}$ NMR spectroscopy [JEOL GSX-400, solvent: $\mathrm{CDCl}_{3}$, internal reference: TMS]. No occurrence of racemization of PLLA segment in the obtained 8 arms PEG- $b$-PLLA and 2 arms PEG- $b$-PLLA was checked by ${ }^{13} \mathrm{C}$ NMR spectroscopy [JEOL GSX-400, solvent: $\mathrm{CDCl}_{3}$, internal reference: TMS].

\section{Preparation of Solution Cast Films}

Thin films from star-shaped 8 arms PEG10K- $b$ PLLA35K, 8 arms PEG35K- $b$-PLLA37K and linear 2 arms PEG- $b$-PLLA were prepared by solution cast method. A polymer solution (4 wt \%) in chloroform was cast on a Teflon dish $70 \mathrm{~mm}$ in size, which was then dried at $40^{\circ} \mathrm{C}$ for $2 \mathrm{~d}$. The solidified film was carefully taken off the dish and thoroughly dried for $4 \mathrm{~d}$ in vacuo.

\section{Thermal Analysis of Polymer Films}

$T_{\mathrm{g}}, T_{\mathrm{m}}, \Delta H_{\mathrm{m}}$ of the polymer films were measured by differential scanning calorimetry (DSC; SHIMADZU DSC-60, TA-60WS). Polymer films $(5 \mathrm{mg})$ were quenched with liquid nitrogen, and then first heating run and second heating run were conducted. The temperature range was between $-100^{\circ} \mathrm{C}$ and $200{ }^{\circ} \mathrm{C}$ at a heating rate of $10^{\circ} \mathrm{C} / \mathrm{min}$.

\section{Measurement of Water Absorption in Polymer Films}

The water absorption in polymer films was examined by gravimetric measurement. The polymer films $(10 \mathrm{~mm} \times 20 \mathrm{~mm})$ were weighted after thorough drying $\left(W_{\text {dry }}\right)$ and immersed in $1 / 15 \mathrm{M} \mathrm{KH}_{2} \mathrm{PO}_{4}-\mathrm{NaHPO}_{4}$ buffers (PBS; $\mathrm{pH}=7.4, \mathrm{I}=0.14$ ) at $37^{\circ} \mathrm{C}$. After predetermined times up to $120 \mathrm{~min}$, the polymer films were taken out from the PBS, wiped dry with KIMWIPE $^{\circledR}$, and weighted again immediately $\left(W_{\text {wet }}\right)$. Water absorption of polymer films was determined as follows: Water absorption $(\%)=\left[\left(W_{\text {wet }}-\right.\right.$ $\left.\left.W_{\text {dry }}\right) / W_{\text {dry }}\right] \times 100$.

\section{Degradation Test of Polymer Films}

The biodegradation behavior of polymer films was estimated by weight loss and molecular weight reduction. The polymer films $(10 \mathrm{~mm} \times 20 \mathrm{~mm})$ were weighted after thorough drying $\left(W_{0}\right)$ and immersed in PBS at $37^{\circ} \mathrm{C}$. After $1,2,4,7,14$ and $28 \mathrm{~d}$, the polymer films were taken out from PBS, washed with water, dried in vacuo, and then weighted again $\left(W_{\mathrm{t}}\right)$. Molecular weight of polymer films after degradation $\left(M_{\mathrm{t}}\right)$ was measured by GPC. The weight loss was determined as follows: Weight loss $(\%)=\left[\left(W_{0}-W_{\mathrm{t}}\right) /\right.$ $\left.W_{0}\right] \times 100$. The surface of polymer films degraded for $28 \mathrm{~d}$ in PBS was observed by using a JEOL JSM35 scanning electron microscope (SEM).

\section{Measurement of Mechanical Property in Polymer Films}

Tensile tests were performed using dry cast film by AUTOGRAPH AGS-J series equipment (SHIMADZU) at room temperature. Test samples of the polymer film (dumbbell-shaped; both ends: $5 \mathrm{~mm}$, middle: $2 \mathrm{~mm}$, length: $40 \mathrm{~mm}$, thickness: 100 $\mu \mathrm{m})$ were prepared and subjected to the tensile test at an extension rate of $10 \mathrm{~mm} / \mathrm{min}$. Ten samples were tested and the results were averaged.

\section{TEM Observation of Polymer Films}

The samples for TEM observation were prepared from block copolymer cast films by the following procedure. The copolymer cast films were embedded in epoxy resin, and then the embedded films were cut as ultrathin sections with thickness of $c a .50 \mathrm{~nm}$ by an ultramicrotome. The sections were stained with $\mathrm{OsO}_{4}$ for $4 \mathrm{~h}$ and their microphase-separated structures of block copolymer films were observed by a transmission electron microscope (TEM), JEOL JEM-1210 under an acceleration voltage of $100 \mathrm{kV}$.

\section{RESULTS AND DISCUSSION}

\section{Hydrodynamic Radius of 8 arms PEG and 2 arms PEG}

It is well known that the excretion efficiency of PEG out of the body through kidney goes down in 2 arms PEG having higher molecular weight than $20,000 .{ }^{17}$ So, the use of 2 arms PEG having higher molecular weight than 20,000 is not desirable in the design of PEG-PLLA block copolymer as an implantable material. Namely, low hydrophilicity and no strong mechanical strength of PEG-PLLA block copolymer were presumed to be derived by use of 2 arms PEG having lower molecular weight than 20,000. Recently, Yamaoka and co-workers proposed the design of multi-block copolymer to overcome these problems. ${ }^{18}$ The results of DLS measurement of 8 arms PEG and 2 arms PEG in water are shown in Figure 1. The hydrodynamic radius of $2 \mathrm{arms}$ PEG20K $\left(M_{\mathrm{n}}=2.0 \times 10^{4}\right)$ was $12.1 \mathrm{~nm}$ while those of 8 arms PEG20K and 8 arms PEG35K were $6.7 \mathrm{~nm}$ 


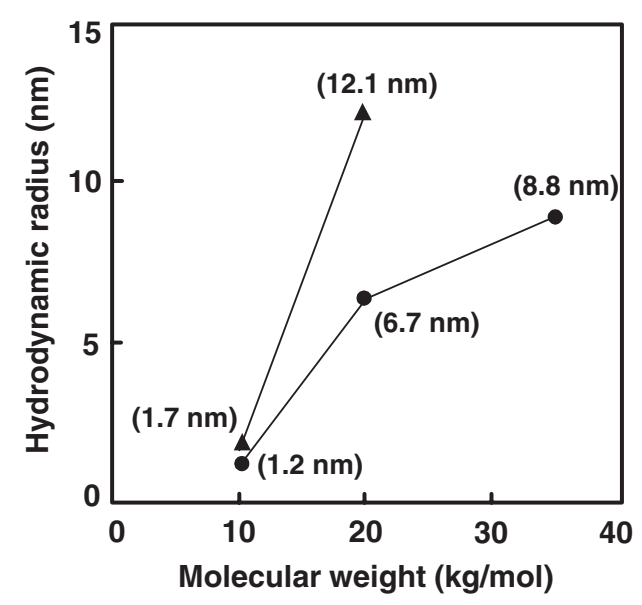

Figure 1. Hydrodynamic radius of star-shaped 8 arms PEG

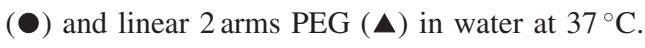

and $8.8 \mathrm{~nm}$, respectively. Namely, it was confirmed that hydrodynamic radius of star-shaped 8 arms PEG was smaller than linear 2 arms PEG having the same molecular weight; The excretion out of the body can be expected for 8 arms PEG35K. So, 8 arms PEG35K was suggested to be useful as a central unit in starshaped PEG-PLLA block copolymer for application of bioabsorbable biomaterial. Thus, the obtained 8 arms PEG35K- $b$-PLLA matrix can be expected to have suitable mechanical strength and higher hydrophilicity as a bioabsorbable soft material.
Synthesis of Star-shaped 8 arms PEG-b-PLLA

8 arms PEG- $b$-PLLA was synthesized by ring-opening polymerization of L-lactide using 8 arms PEG $\left(M_{\mathrm{n}}: 10,000\right.$ and 35,000$)$ as an octafunctional macroinitiator. The ${ }^{1} \mathrm{H}$ NMR spectrum of the synthesized 8 arms PEG10K- $b$-PLLA35K with the peak assignment is shown in Figure 2A. The obtained ${ }^{1} \mathrm{H}$ NMR spectrum indicated that the polymerization of $\mathrm{L}$ lactide proceeded from the eight hydroxyl groups of 8 arms PEG10K, specifically by the disappearance of terminal hydroxyl groups of 8 arms PEG $\left(-\mathrm{CH}_{2} \mathrm{OH}\right.$, $4.6 \mathrm{ppm}$ ) and the disappearance of methylene groups neighboring terminal hydroxyl groups of $8 \mathrm{arms}$ PEG (- $\left.\mathrm{CH}_{2} \mathrm{OH} ; 3.74 \mathrm{ppm}\right)$ that were shifted to $4.12-$ $4.30 \mathrm{ppm}\left(-\mathrm{CH}_{2} \mathrm{OCHCH}_{3}\right.$; E peak), respectively. Additionally, all the obtained block copolymer gave a sharp peak with one top in the GPC curve (data not shown). These results revealed that the block copolymerization of L-lactide proceeded homogeneously from all the hydroxyl groups in 8 arms PEG. The molecular weight of 8 arms PEG- $b$-PLLA was calculated from integral ratio of the peaks $(b+e)$ to the peak $d$ in the ${ }^{1} \mathrm{H}$ NMR spectrum. Table I summarizes the results of block copolymerization of L-lactide with 8 arms PEG or 2 arms PEG. We used code name such as 8 arms PEG10K- $b$-PLLA35K $(8-10 \mathrm{~K}$, content of PEG unit: $24 \mathrm{wt} \%$ ), where $10 \mathrm{~K}$ means the molecular weight of 8 arms PEG unit is 10,000 and $35 \mathrm{~K}$ means the total molecular weight of PLLA segments are
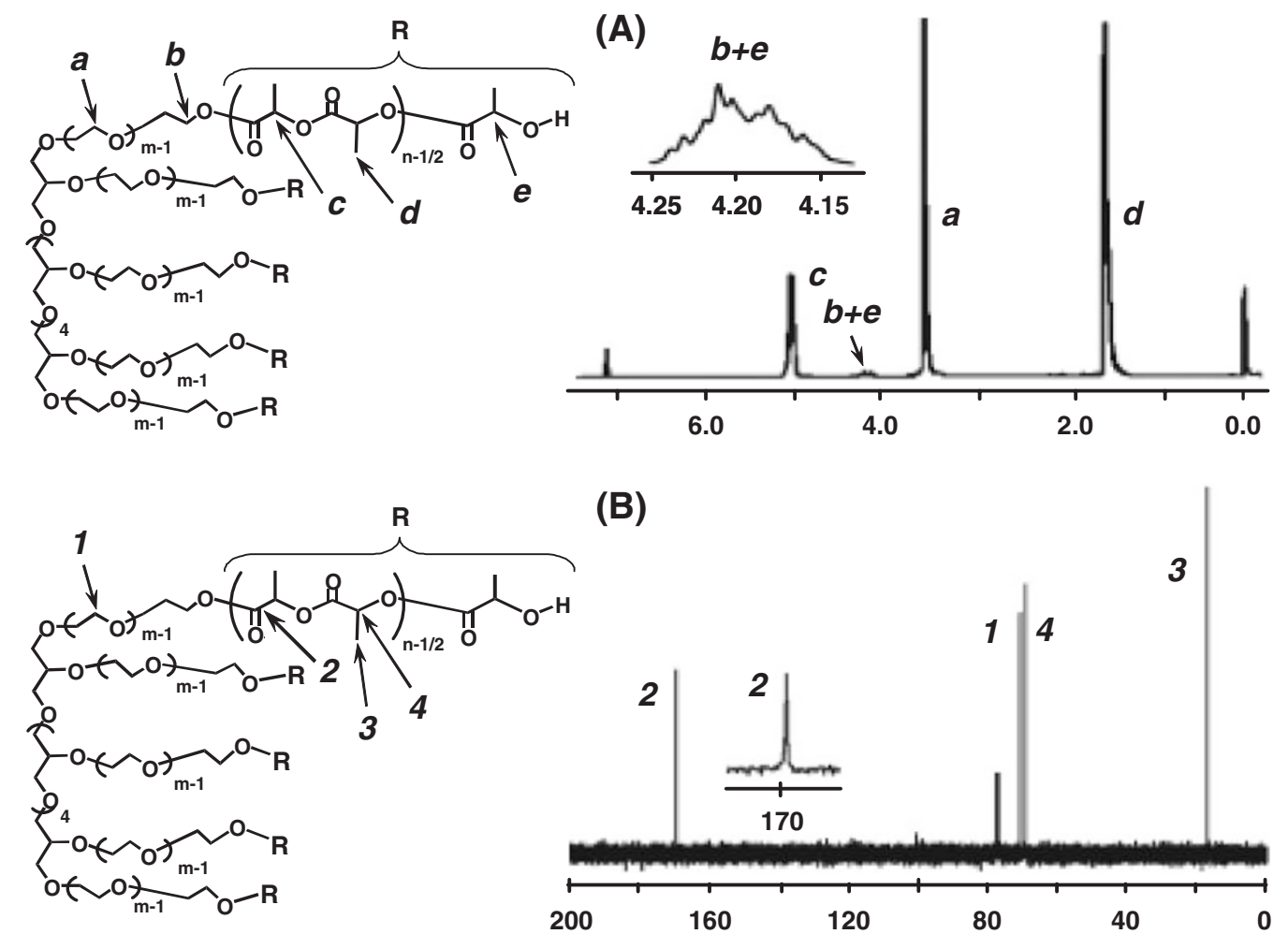

Figure 2. (A) ${ }^{1} \mathrm{H}$ NMR spectrum and (B) ${ }^{13} \mathrm{C}$ NMR spectrum of star-shaped 8 arms PEG10K-PLLA35K block copolymer. 
Table I. Results of polymerization of L-lactide with 8 arms PEG or 2 arms PEG ${ }^{\text {a }}$

\begin{tabular}{|c|c|c|c|c|c|c|}
\hline Block copolymer & $\mathrm{M} / \mathrm{OH}^{\mathrm{b}}$ & $\begin{array}{c}\text { yield } \\
(\%)\end{array}$ & $M_{\mathrm{n}}^{\mathrm{c}}$ & $M_{\mathrm{w}} / M_{\mathrm{n}}^{\mathrm{d}}$ & {$[\mathrm{m}, \mathrm{n}]^{\mathrm{e}}$} & $\begin{array}{c}\text { PEG unit } \\
\text { content } \\
(\text { wt } \%)\end{array}$ \\
\hline 8 arms PEG35K- $b$-PLLA37K (8-35 K) & 40 & 72.9 & 71,400 & 1.2 & {$[98,32]$} & 48 \\
\hline 8 arms PEG10K- $b$-PLLA35K $(8-10 \mathrm{~K})$ & 40 & 76.6 & 44,600 & 1.3 & {$[28,30]$} & 24 \\
\hline 2 arms PEG10K- $b$-PLLA33K (2-10 K) & 130 & 83.5 & 43,400 & 1.2 & {$[227,114]$} & 23 \\
\hline
\end{tabular}

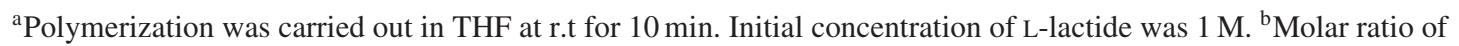
L-lactide to hydroxy groups of 8 arms PEG in feed. ${ }^{c}$ Estimated by ${ }^{1} \mathrm{H}$ NMR (solvent: $\mathrm{CDCl}_{3}$ ). ${ }^{\mathrm{d}}$ Estimated by FPC (eluent: DMF, standared: PEG). ${ }^{\mathrm{e}} \mathrm{m}$ and $\mathrm{n}$ means the degrees of polymerization of ethylene glycol unit and L-lactide unit in each arm of the block copolymer, respectively.

35,000 , respectively. As a control copolymer, 2 arms PEG10K- $b$-PLLA33K (2-10 K, content of PEG unit: $23 \mathrm{wt} \%$ ) having the same PEG and PLLA molecular weight against $8-10 \mathrm{~K}$ was synthesized to investigate the effects of molecular architecture focusing on star-shape and linear structures. Moreover, 8 arms PEG35K- $b$-PLLA37K (8-35 K, content of PEG unit: 48 wt \%) with larger PEG and same PLLA molecular weight compared with $8-10 \mathrm{~K}$ was synthesized to investigate the effects of branched PEG chains length on its physicochemical properties. The solution cast films having a thickness of $c a$. $100 \mu \mathrm{m}$ were prepared from these block copolymers, and used subsequently for investigation of their physicochemical properties.

The ${ }^{13} \mathrm{C}$ NMR spectrum of 8 arms PEG10K$b$-PLLA35K with peak assignment is shown in Figure 2B. It was previously reported that the peak at $169 \mathrm{ppm}$ assigned to the $\mathrm{C}=\mathrm{O}$ carbon atom of racemized PLLA appeared as the broad triplet peaks. ${ }^{19}$ However, the $\mathrm{C}=\mathrm{O}$ peak of PLLA at $169 \mathrm{ppm}$ in the obtained 8 arms PEG10K- $b$-PLLA35K was singlet and sharp. In the cases of other two copolymers ( 8 arms PEG35K- $b$-PLLA37K and 2 arms PEG10K$b$-PLLA33K), the same results were obtained (data not shown). These results indicated that the racemization did not occur in the polymerization of L-lactide under our reaction condition.

\section{Thermal Property of Polymer Films}

$T_{\mathrm{m}}$ of $8 \mathrm{arms}$ PEG10K film was observed at $47.6^{\circ} \mathrm{C}$, whereas that of $2 \mathrm{arms}$ PEG10K film appeared at $65.6^{\circ} \mathrm{C}$. The reduction of $T_{\mathrm{m}}$ owing to star-shaped structure was attributed to the disruption of the orderly fold pattern of the PEG crystal.

Table II summarizes the results of thermal analysis in the block copolymer films, PEG films, and PLLA53K film. $T_{\mathrm{g}}$ and $T_{\mathrm{m}}$ of $8 \mathrm{arms}$ PEG10K- $b-$ PLLA35K and 2 arms PEG10K- $b$-PLLA33K films were lower than those of PLLA53K film. For example, $T_{\mathrm{g}}$ and $T_{\mathrm{m}}$ of 8 arms PEG10K- $b$-PLLA35K film was observed at $-7.9^{\circ} \mathrm{C}$ and $118.9^{\circ} \mathrm{C}$, respectively,
Table II. Thermal properties of copolymer films ${ }^{\mathrm{a}}$

\begin{tabular}{lrrrr}
\hline \multirow{2}{*}{ Film } & $T_{\mathrm{g}}$ & \multicolumn{2}{c}{$T_{\mathrm{m}}\left({ }^{\circ} \mathrm{C}\right)$} & $X_{\mathrm{c}}$ of PLLA $^{\mathrm{b}}$ \\
\cline { 3 - 4 } & $\left({ }^{\circ} \mathrm{C}\right)$ & PEG & PLLA & $(\%)$ \\
\hline 8-35 K & -12.9 & 41.3 & N.D. $^{\mathrm{c}}$ & 0.0 \\
8-10 K & -7.9 & 51.3 & 118.9 & 1.8 \\
$2-10 \mathrm{~K}$ & 36.3 & 58.7 & 171.9 & 37.5 \\
\hdashline PLLA53K & 50.2 & - & 176.4 & 44.2 \\
8 arms PEG35K & -46.2 & 59.3 & - & - \\
8 arms PEG10K & -54.8 & 47.6 & - & - \\
2 arms PEG10K & -41.5 & 65.6 & - & - \\
\hline
\end{tabular}

a Determined by DSC measurement. The sample was heated at $10^{\circ} \mathrm{C} / \mathrm{min}$. The temperature ranged between $-100^{\circ} \mathrm{C}$ and $200^{\circ} \mathrm{C}$. ${ }^{\mathrm{b}}$ Crystallinity $\left(X_{\mathrm{c}}\right)$ was estimated from $\Delta H$ values of PLLA. ${ }^{\mathrm{c}}$ Not detected.

while those of 2 arms PEG10K- $b$-PLLA33K film appeared at $36.3{ }^{\circ} \mathrm{C}$ and $171.9^{\circ} \mathrm{C}$, respectively. So, the crystallinity $\left(X_{\mathrm{c}}\right)$ of PLLA in the copolymer film was evaluated. The $X_{\mathrm{c}}$ of PLLA was determined as follows: $X_{\mathrm{c}}(\%)=\left(\Delta H_{\mathrm{m}} / \Delta H_{\mathrm{m}, 100 \%}\right) \times 100$, where $\Delta H_{\mathrm{m}}$ was the melting enthalpy of PLLA in the copolymer films, $\Delta H_{\mathrm{m}, 100 \%}$ was the melting enthalpy of perfect PLLA crystal $(-93.7 \mathrm{~J} / \mathrm{g})$. Although $X_{\mathrm{c}}$ of PLLA for 2 arms PEG10K- $b$-PLLA33K film was $37.5 \%$, that of 8 arms PEG10K- $b$-PLLA35K film was $1.8 \%$. Considering no occurrence of racemization in our system, these results in the $8 \mathrm{arms}$ PEG10K- $b$-PLLA35K film indicated that the formation of the large PLLA crystal domains was suppressed by introduction of star-shaped 8 arms PEG as a central unit. On the contrary, it was suggested that the large PLLA crystal domains were formed in the 2 arms PEG10K- $b$-PLLA33K film. In addition, no endothermic melting peak of the PLLA crystal domains was observed in 8 arms PEG35K- $b$-PLLA37K film, namely the 8 arms PEG35K- $b$-PLLA37K film had only the PEG crystal domains. Consequently, the star-shaped 8 arms PEG10K- $b$-PLLA35K and 8 arms PEG35K- $b$-PLLA37K films were expected to show soft nature compared with linear 2 arms PEG10K- $b$ PLLA33K film. 


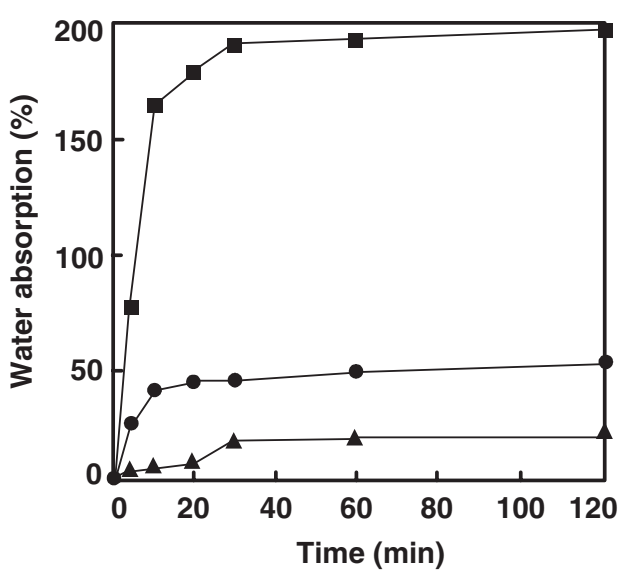

Figure 3. Time courses of the water absorption of copolymer films at room temperature. (ロ) 8-35 K film, (•) 8-10 K film, (A) 2-10 K film.

\section{Water Absorption Ability of Polymer Films}

Investigating the interaction between water and any material to be used as a biological implant is very important. So, we evaluated the water absorption ability of the PEG-PLLA copolymer films. The time-course curves of water absorption of the 8 arms PEG- $b$-PLLA films in PBS compared with that of the 2 arms PEG$b$-PLLA film are shown in Figure 3. In both the star-shaped 8 arms PEG35K- $b$-PLLA37K and 8 arms PEG10K- $b$-PLLA35K films, water absorption started immediately after immersion in PBS and then leveled off after $15 \mathrm{~min}$ (equilibrium water absorption). In comparison, the linear 2 arms PEG10K- $b$-PLLA33K film exhibited a much slower water absorption rate, and did not level off until after $30 \mathrm{~min}$. In spite of the same PEG volume fraction in the 8 arms PEG10K- $b$-PLLA35K film and the 2 arms PEG10K$b$-PLLA33K film, the water absorption ability of the 8 arms PEG10K- $b$-PLLA35K film was higher than that of the 2 arms PEG10K- $b$-PLLA33K film. This directly implies that the lower crystallinity of PLLA in the 8 arms PEG10K- $b$-PLLA35K film, which makes the internal polymer structure more accessible to water, resulted in a larger degree of hydration of the PEG chains in the star-shaped 8 arms PEG10K- $b$ PLLA35K films than in the linear 2 arms PEG10K$b$-PLLA33K film. Thus, it was concluded that the water absorption capacity of the PEG-PLLA block copolymer films depended on the crystallinity of the PLLA in the block copolymer film. In addition, the equilibrium percentage of water absorption for the 8 arms PEG35K- $b$-PLLA37K film was very high (200\%) compared with that for the 8 arms PEG10K$b$-PLLA35K film (55\%). When considering that the crystallinity of PLLA was the same degree with the 8 arms PEG35K- $b$-PLLA37K film and the 8 arms PEG10K- $b$-PLLA35K film, it was possible to say that

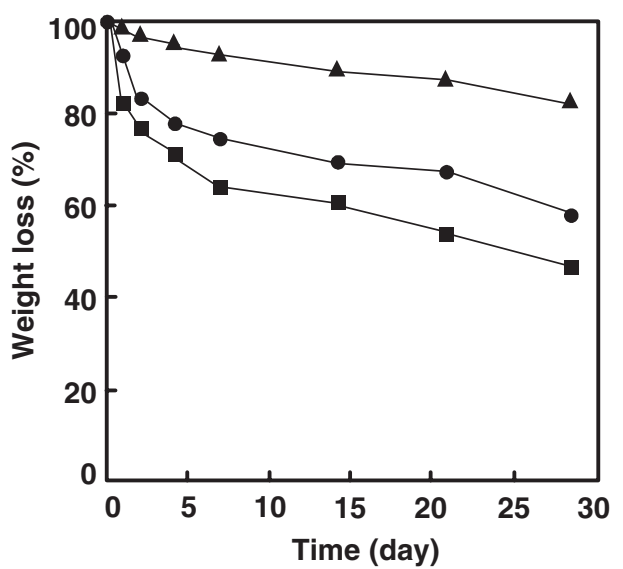

Figure 4. Time courses of weight reduction of copolymer films in PBS ( $\mathrm{pH}=7.4 ; \mathrm{I}=0.14$ ) at $37^{\circ} \mathrm{C}$. (四 $8-35 \mathrm{~K}$ film, (•) 8-10 K film, (A) 2-10 K film.

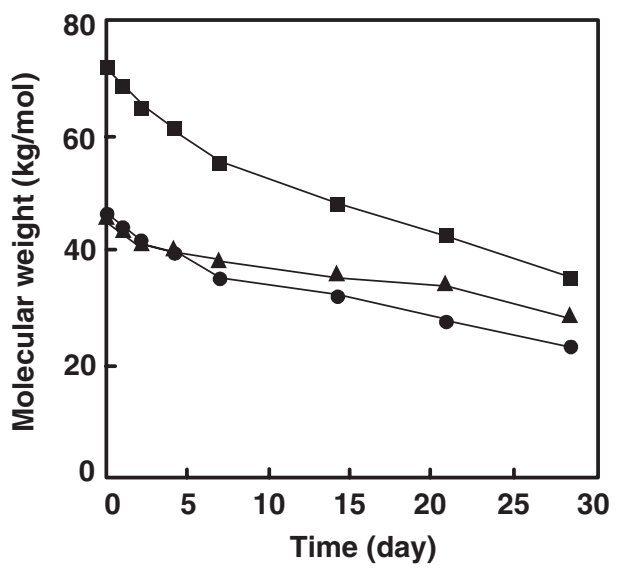

Figure 5. Time courses of molecular weight reduction of co-

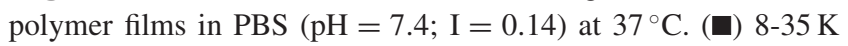
film, (•) 8-10 K film, (\) 2-10 K film.

the higher water absorption ability of the 8 arms PEG35K- $b$-PLLA37K film was caused by the larger PEG volume fraction in the copolymer film. As a result of this very high value, the 8 arms PEG35K$b$-PLLA37K film was swollen with water and exhibited a hydrogel-like nature.

\section{Degradation Behavior of Polymer Films}

The degradation behavior of the copolymer films was evaluated in vitro. Figures 4 and 5 show the time course curves of the weight loss and molecular weight reduction of copolymer films during the biodegradation test in $\mathrm{PBS}$ at $37^{\circ} \mathrm{C}$, respectively. Although the degree of molecular weight reduction for 8 arms PEG10K- $b$-PLLA35K film was similar to that for 2 arms PEG10K- $b$-PLLA33K film, the rate of weight loss for star-shaped 8 arms PEG10K- $b$-PLLA35K film was effectively faster than that of linear 2 arms PEG10K- $b$-PLLA33K film. On the contrary, the weight loss of the 8 arms PEG35K- $b$-PLLA37K film 

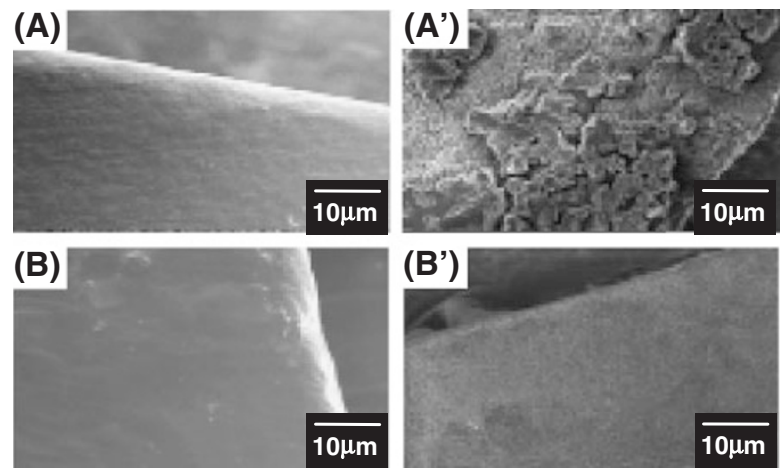

Figure 6. SEM images of copolymer film surfaces before and after degradation test. (A) $8-10 \mathrm{~K}$ film before degradation, (A') $8-10 \mathrm{~K}$ film after $28 \mathrm{~d}$ degradation, (B) $2-10 \mathrm{~K}$ film before degradation, (B') 2-10 K film after $28 \mathrm{~d}$ degradation.

was faster a little than those of the 8 arms PEG10K- $b$ PLLA35K film only. These results in the weight loss mainly related with the crystallinity of PLLA; the rate of weight loss for PEG-PLLA copolymer film increased with decreasing the crystallinity of PLLA in the copolymer film. In order to investigate the state change of the $8 \mathrm{arms}$ PEG10K- $b$-PLLA35K and 2 arms PEG10K- $b$-PLLA33K film surfaces before and after degradation test, SEM observation was performed (Figure 6). Although both films had smooth surface before degradation test, the surface state of both films immersed in PBS for $28 \mathrm{~d}$ was transformed to be rough. Especially, the degree of roughness derived by degradation for 8 arms PEG10K- $b$-PLLA35K film was very large compared with that for 2 arms PEG10K- $b$-PLLA33K film. Considering the rate of molecular weight reduction for 8 arms PEG10K$b$-PLLA35K film was similar to that for 2 arms PEG10K- $b$-PLLA33K, the degradation pattern of star-shaped 8 arms PEG10K- $b$-PLLA35K film was suggested to be substantially different from that of the linear 2 arms PEG10K- $b$-PLLA33K film.

\section{Mechanical Property of Polymer Films}

The tensile properties of dry PEG-PLLA copolymer films and equilibrium water absorption PEG-PLLA copolymer films were evaluated from their stressstrain curves, as shown in Figures 7A and 7B. The tensile strength of dry star-shaped 8 arms PEG10K$b$-PLLA35K film (6.3 MPa) was lower than that of dry linear 2 arms PEG10K- $b$-PLLA33K film (23.7 $\mathrm{MPa})$. Moreover, the Young's modulus of dry 8 arms PEG10K- $b$-PLLA35K film (150 MPa) was very lower than that of dry 2 arms PEG10K- $b$-PLLA33K film $(1,190 \mathrm{MPa})$. These results indicated that the softness of the PEG-PLLA block copolymer film was derived by strong suppression to form the PLLA crystal domains, that is, the softness of the 2 arms PEG10K- $b$ -
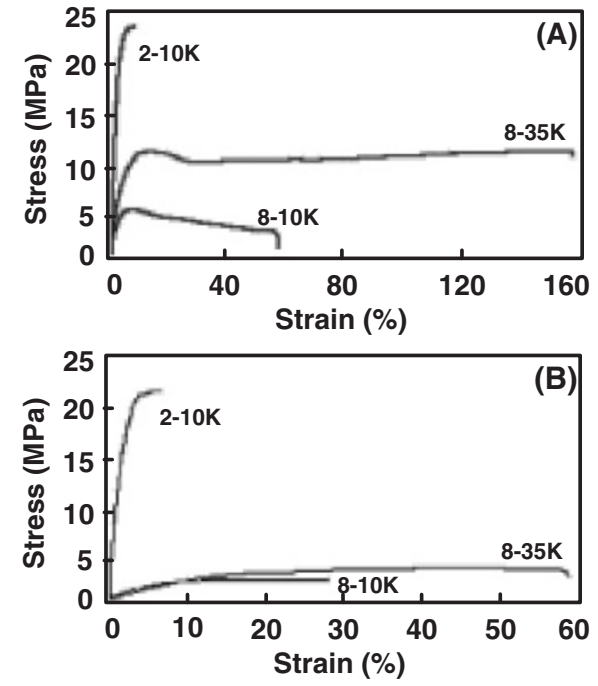

Figure 7. Stress-strain curves of (A) dry copolymer films and (B) equilibrium water absorption films at room temperature.

PLLA353K film was rather lower than that of the 8 arms PEG10K- $b$-PLLA35K film which hardly formed the PLLA crystal domains. Although the ability to form the PLLA crystal domains of the 8 arms PEG10K- $b$-PLLA35K film was very lower than that of the 2 arms PEG10K- $b$-PLLA33K film, the elongation at break of the 8 arms PEG10K- $b$-PLLA35K film (57\%) was higher than that of the 2 arms PEG10K$b$-PLLA33K film (12\%). Moreover, the 8 arms PEG35K- $b$-PLLA37K film with longer branched PEG chains compared with the 8 arms PEG10K- $b$ PLLA35K film showed the highest elongation at break $(155 \%)$. These results indicated that the star-shaped structure and the longer branched PEG chains were important to obtain the high elongation at break in the PEG-PLLA block copolymer film. Figure 7B shows stress-strain curves of equilibrium water absorption copolymer films. The breaking strength and elongation at break of equilibrium water absorption 8 arms PEG10K- $b$-PLLA35K film were $2.8 \mathrm{MPa}$ and $27 \%$, respectively, while those of 2 arms PEG10K- $b$ PLLA33K film were $22.3 \mathrm{MPa}$ and $7.3 \%$, respectively. Although the 8 arms PEG35K- $b$-PLLA37K film had as much as $200 \%$ of water absorption ability, the 8 arms PEG35K- $b$-PLLA37K film exhibited large elongation at break (57\%). Consequently, it was assumed that the mechanical properties such as softness and tenacity of the 8 arms PEG35K- $b$-PLLA37K film were given because of aggregation ability to form the highly ordered PLLA network. Therefore, TEM observations of these block copolymer films (cross section) were performed to investigate the aggregation structure of the PLLA chains (Figure 8). The dark domains indicated the PLLA domains which were stained with $\mathrm{OsO}_{4}$ and the unstained bright do- 


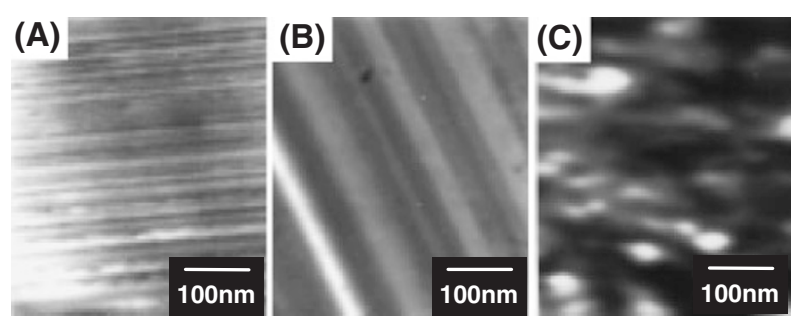

Figure 8. TEM images of copolymer films (cross section). (A) $8-35 \mathrm{~K}$ film, (B) $8-10 \mathrm{~K}$ film, (C) $2-10 \mathrm{~K}$ film.

mains showed the PEG domains. The linear 2 arms PEG10K- $b$-PLLA33K film showed miscellaneous phase separated structure, whereas the star-shaped 8 arms PEG10K- $b$-PLLA35K film and 8 arms PEG35K- $b$-PLLA37K film showed lamellar structure between PLLA domains and PEG domains. These results indicated that star-shaped structure was available to form the ordered phase separated structure in the case of PEG-PLLA block copolymer. Consequently, the softness nature of the 8 arms PEG10K- $b$ PLLA35K film and the 8 arms PEG35K- $b$-PLLA37K film related to the formation of lamellar structure in the films. In other words, in that the hard PLLA domains were put in the soft PEG domains, softness nature of the 8 arms PEG10K- $b$-PLLA35K film and the 8 arms PEG35K- $b$-PLLA37K film was gotten. In addition, the 8 arms PEG35K- $b$-PLLA37K film showed homogenously lamellar structure with smaller PLLA domain size $(10 \mathrm{~nm})$ compared with that of the 8 arms PEG10K- $b$-PLLA35K film $(80 \mathrm{~nm})$ having same PLLA chain length. This result suggested that the aggregation force to form the PLLA domains in 8 arms PEG35K- $b$-PLLA37K film was stronger than that in the 8 arms PEG10K- $b$-PLLA35K film. These differences in the uniformity as well as size of the PLLA domains were important factor which influenced the mechanical property of the PEG-PLLA copolymer film, that is, highly elongation at break of the 8 arms PEG35K- $b$-PLLA37K film was gotten by formation of the ordered periodic lamellar structure composed of the PLLA domains and the PEG domains.

\section{CONCLUSIONS}

The star-shaped block copolymers having amphiphilic structure composed of 8 arms PEG and PLLA were synthesized through ring-opening polymerization of L-lactide with 8 arms PEG10K or 8 arms PEG35K as a macroinitiator. The resultant 8 arms PEG10K- $b$-PLLA35K cast films showed drastically lower PLLA crystallinity and tensile strength as compared with correspondence linear 2 arms PEG10K- $b$ PLLA33K film because the ordered PLLA domains with lamellar structure were formed in the star-shaped
8 arms PEG10K- $b$-PLLA35K film. In other words, in that the hard PLLA domains were put in the soft PEG domains, softness nature of the 8 arms PEG10K- $b$-PLLA35K film was gotten. Moreover, the homogeneous fine PLLA domains with highly ordered lamellar structure were formed in the $8 \mathrm{arms}$ PEG35K- $b$-PLLA37K film.

This result suggested that the aggregation ability to form the PLLA domains in 8 arms PEG35K- $b$ PLLA37K film was stronger than that in the 8 arms PEG10K- $b$-PLLA35K film. Consequently, the 8 arms PEG35K- $b$-PLLA37K film had the higher water absorption ability and larger elongation at break. Namely, the forming of the homogeneous fine PLLA domains was important in the high water absorption ability, degradation rate as well as desirable mechanical properties to be compatible as implantable soft biomaterial. The 8 arms PEG35K- $b$-PLLA37K film was expected to exhibit a biologically inert surface having cell anti-adhesive property owing to the highly ordered PEG domains. So, a future report will detail the results of in vitro tests such as water contact angle, surface morphology, protein adsorption and cell adhesion onto the 8 arms PEG35K- $b$-PLLA37K film that will determine the availability of this material as a bioabsorbable adhesion-prevention membrane.

Acknowledgment. The authors thank NOF Co. for the supply of 8 arms PEG. This work was financially supported by a Grant-in-Aid for Research (B) (17300163) from the Japan Society for the Promotion of Science. This work was carried out as a study in the High-Tech Research Center Project supported by the Ministry of Education, Culture, Sports, Science and Technology, Japan.

\section{REFERENCES}

1. Y. Matsusue, T. Yamamuro, M. Oka, Y. Shikinami, S. H. Hyon, and Y. Ikada, J. Biomed. Mater. Res., 26, 1553 (1992).

2. H. Tsuji and Y. Ikada, Macromolecules, 25, 5719 (1992).

3. Y. Kimura, Y. Matsuzaki, H. Yamane, and T. Kitao, Polymer, 30, 1342 (1989).

4. M. Malin, M. Hiljanen-vainio, T. Karjalainen, and J. Seppala, J. Appl. Polym. Sci., 59, 1289 (1996).

5. F. Tasaka, Y. Ohya, and T. Ouchi, Macromolecules, 32, 6386 (1999).

6. F. Tasaka, Y. Ohya, and T. Ouchi, Macromolecules, 34, 5494 (2001).

7. O. Martin and L. Averous, Polymer, 42, 6209 (2001).

8. Y. Ohya, S, Maruhashi, and T. Ouchi, Macromolecules, 31, 4662 (1998).

9. T. Ouchi, T. Kontani, and Y. Ohya, Polymer, 44, 3927 (2003).

10. T. Ouchi, T. Kontani, and Y. Ohya, J. Polym. Sci., Part A: 
Polym. Chem., 41, 2462 (2003).

11. D. Cohn and H. Younes, J. Biomed. Mater. Res., 22, 993 (1988).

12. L. Youxin, C, Volland, and T. Kissel, J. Controlled Release, 32, 121 (1994).

13. A. Finne and A. C. Albertsson, Biomacromolecules, 3, 684 (2002).

14. Y. K. Choi, Y. H. Bae, and S. W. Kim, Macromolecules, 31, 8766 (1998).
15. Y. Li and T. Kissel, Polymer, 39, 4421 (1998).

16. Y. K. Choi, Y. H. Kim, Bae, and S. W. Kim, Proc. Int. Symp. Control. Relat. Bioact. Mater., 23, 349 (1996).

17. T. Yamaoka, Baiomateriaru, 21, 37 (2003).

18. T. Yamaoka, Y. Takahashi, T. Fujisato, C. W. Lee, T. Tsuji, T. Ohta, A. Murakami, and Y. Kimura, J. Biomed. Mater. Res., 54, 470 (2001).

19. F. Chabot, M. Vert, S. Chapelle, and P. Granger, Polymer, 24, 53 (1983). 